The scheme of the work is purely ethnographical. Anthropometry, in India at least, has fallen into some discredit since the death of Sir $H$. Risley, partly because it is now realised that the materials on which he based his conclusions were incomplete, partly because the groups which he discriminated have been shown to be less completely isolated than he supposed.

Much space might have been saved by compression. If, for instance, a set of standard accounts of birth, marriage, and death observances were once for all prepared, it would save constant repetition, and it would be necessary only to refer to variations from the normal practice. But the author has followed here the example of other writers in the series. When these monographs come to be revised, the scheme of arrangement might with advantage be reconsidered.

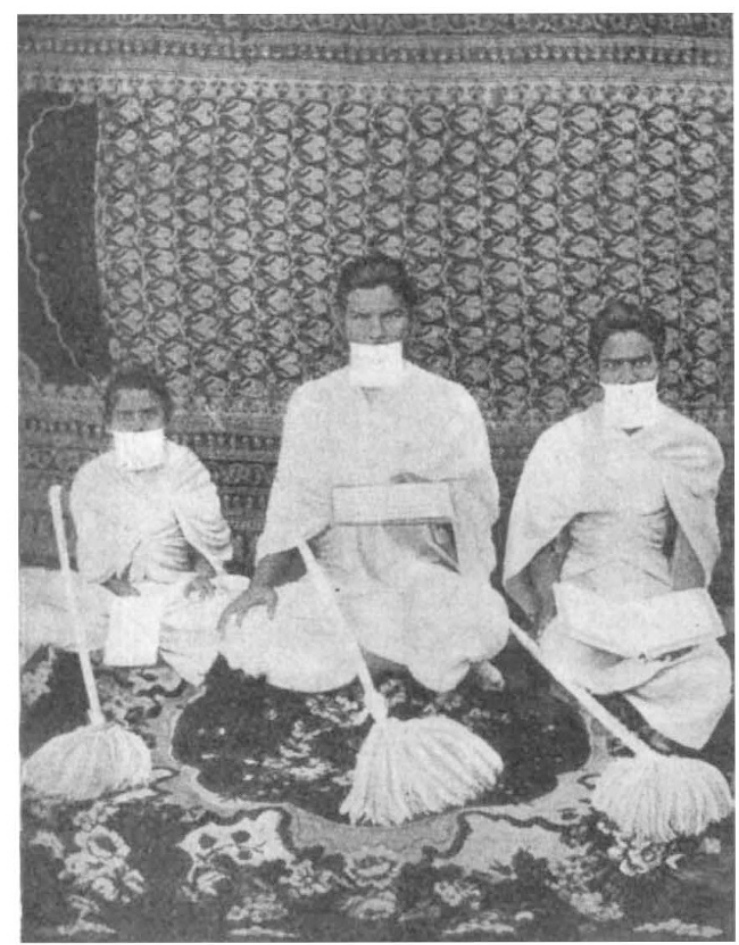

FIG. 2.-Jain Ascetics with cloth before mouth and sweeping brush. Reproduced from "The Tribes and Castes of the Central Provinces of India."

In these criticisms we must not be supposed to underrate the value of this important contribution to the ethnography of India. Every article shows the assiduous care with which the facts have been investigated; the articles are well arranged, and in the case of the less known tribes, like the Gonds, Bhils, and Korkus, much novel information is supplied, while other less distinctively local groups, like Marathas, Jats, Gujars, and Rajputs, are adequately dealt with, the articles displaying full acquaintance with the work done in other Provinces, which is invariably quoted with full acknowledgment. In almost every page there are accounts of quaint usages and beliefs of the highest interest. The work is provided with an excellent set of photographs, and its format is what might have been expected from the reputation of the publishers.

The untimely death of Mr. Russell is a serious loss to anthropology, and it is sad to think that it occurred on the eve of the publication of a book which was the work of his life, and will do much to preserve the memory of his learning and devotion to science.

BIRDS' SONGS AND THE DIATONIC SCALE.

A LETTER from Dr. R. H. Bellairs, of ChelA tenham, appeared in the Times of June I4, describing the performance "by a wild bird, probably a thrush, of the arpeggio of the common chord in tune, absolutely in tune." This was followed by other letters, of which the Times printed three and gave a summary of the rest. Their contents amount to this: blackbirds do ozcasionally sing a few notes in our diatonic scale; thrushes less often. Only one other bird was mentioned, "the whitethroat or willow-wren," which leaves the identity of the species doubtful; and neither whitethroat nor willow-wren has ever even dimly suggested to me the use of our musical scale. But as the voices of blackbird and thrush do now and then make this suggestion, I will venture, at the Editor's request, to say a few words on the subject.

Few ornithologists are musicians, and few musicians are ornithologists, so that a knowledge of the elementary facts of the two sciences (if I may for the moment consider music as a science) is not a common acquisition. But if we are to judge of the songs of birds by reference to the diatonic scale, we must be quite clear about the following two facts: First, our present musical scale is an artificial selection, the result of a long evolutionary process, from innumerable possible intervals within the octave, and does not seem to be based on any natural human instinct, prompting to one particular selection rather than another. (See the article "Scale" in Grove's "Dictionary of Music," or Dr. Pole's "Philosophy of Music," chaps. v. and vii.)

Secondly, the vocal instrument of a bird is not constructed so as to produce with any readiness the tones of any scale consisting of fixed intervals. The pitch of the bird's notes is regulated by muscles attached to the windpipe, which is as elastic as the body of a worm; and a moment's thought will show that this is not an apparatus suited for producing a fixed succession of sound-intervals. Our reed instruments are more like the bird's organ than any others, but they are of hard material, with air-holes and a mechanism based on mathematical principles.

Combining these two facts, we may safely conclude that it needs a muscular effort, and probably a strong one, for a bird to produce anything like a tune on our scale; but at the same time it is not impossible where the notes are produced slowly and deliberately, as in the blackbird's song, and to some extent in that of the thrush. It would seem that these birds are occasionally prompted to such

NO. 2435, VOL. 97$]$ 
an effort by an imitative instinct which is strong in all birds that sing vigorously; and they succeed in imitating with something like accuracy church bells or other musical sounds made by human beings on the diatonic scale. Sometimes this accuracy in the production of intervals may be the result of accident rather than imitation.

The difficulty that birds have in attaining this accuracy is well shown in a letter by Canon Grevile Livett (June I6), who tells how a blackbird which had attained it one year had to practise hard for a week the following spring before he recovered it. The only bird known to me whose natural "song" is on the diatonic scale is the cuckoo; and I am inclined to think that his third is not often perfect major or minor, but fluctuates between the two.

W. WARDE Fowler.

\section{DR. R. H. SCOTT, F.R.S.}

$D^{R}$. ROBERT HENRY SCOTT died on Sunday, June $r 8$, at the advanced age of eighty-three. He was well known as the chief of the staff of the Meteorological Office from the commencement of the operations of the Meteorological Committee of the Royal Society in 1867 until his retirement on a pension in 1900 , for the first nine years as Director of the Office, and for the remainder of the term as secretary of the Meteorological Council, which took over the direction of the Office in 1876 . He was also secretary of the International Meteorological Committee from its commencement in 1874 until his retirement from office, and his work for that body was held in high esteem by his colleagues in all quarters of the globe. He was a fellow of the Royal Society from i87o. He received the honorary degree of D.Sc. at Dublin in 1898 .

Dr. Scott was born in Dublin in 1833 , a member of a well-known family. His father was a Q.C., and his mother a daughter of the Hon. Charles Brodrick, Archbishop of Cashel; one of his brothers was Headmaster of Westminster, and another was Vicar of Bray and Archdeacon of Dublin. He was educated at Rugby and Trinity College, Dublin, where he was classical scholar in 1853 , and graduated as Senior Moderator in Experimental Physics in 1855 . He studied also at Berlin and Munich, 1856 to 1858 , chiefly chemistry, physics, and mineralogy. He was appointed Lecturer in Mineralogy to the Royal Dublin Society in 1862, and published a Manual of Volumetric Analysis in that year. $\mathrm{He}$ also published in the same year a translation of the second edition of "The Law of Storms, by H. W. Dove, F.R.S.," whose lectures he had attended" at Berlin. The book is dedicated by the author to FitzRoy, who had translated the first edition. It was on that account that Scott was selected by the Meteorological Committee of the Royal Society, of which Sir Edward Sabine was chairman, to take charge of the Meteorological Office. His relations with Sabine were intimate, and he became his executor.

In I86I FitzRoy, whose original duty was exNo. 2435 , VOL. 97$]$ clusively with the meteorology of the sea, had begun the issue of forecasts and storm-warnings, based upon the information collected daily by telegraph and charted on maps. A map of the weather is often a fascinating document, and the impulse towards sharing the information with the general public, all of whom are interested in the weather, is very difficult to resist; but some prominent members of the Royal Society thought that FitzRoy's action in publishing forecasts and storm-warnings was premature. They were interested in the continuous records of weather which they had obtained at Kew Observatory, and thought the proper plan was to have seven other observatories of the same kind and study the maps in relation to the records. The popular interest which FitzRoy's action had aroused secured for them, with the co-operation of the Admiralty and the Board of Trade, a Government grant of Io,oool. a year for the Office, and Scott was entrusted with the direction of the new enterprise, while a marine superintendent, Captain Henry Toynbee, was appointed to carry on the original duty of collecting and discussing marine observations.

The issue of forecasts and storm-warnings was suppressed; but at the request of the Board of Trade the issue of storm-warnings was at once revived. The telegraphic work was developed on careful lines, and the first result of Scott's work appeared in 1876 in a little book entitled "Weather Charts and Storm-Warnings." In I 879 the work had progressed so far that it was deemed appropriate by the Meteorological Council, a very powerful body of scientific experts then in control of the Office, to recommence the issue of forecasts. The issue was commenced on April I of that year, and has continued ever since. This was followed in 1883 by Scott's "Elementary Meteorology," in the "International Scientific Series," which took a foremost place as a textbook of meteorology.

From that time onward Scott devoted his attention mainly to the administration of the Office and to the work of the Meteorological Society, of which he became the foreign secretary, a post which he retained up to the time of his death. He was president in 1884 and 1885 . He still continued to take an active interest in mineralogy and was at one time president of the Mineralogical Society. His other contributions to meteorological literature, whether official or unofficial, were mostly of a technical character.

After the great generalisation of cyclones and anti-cyclones, and their movement, which emerged almost immediately from the study of maps and records, meteorology was found to resist all ordinary endeavours to make it disclose its secrets, and it was not until the development of the study of the upper air from 1896 onwards that a fresh impetus was given to it and we learned that many of the fundamental ideas of atmospheric circulation required revision. But by that time Scott's active interest in the development of the subject had waned.

$\mathrm{He}$ was most methodical and punctilious in the 